\title{
JOSÉ DE ALENCAR E AS CARTAS ABERTAS A FAVOR DA ESCRAVIDÃO: POTENCIALIDADES E LIMITES
}

\section{JOSÉ DE ALENCAR AND THE OPEN LETTERS IN FAVOR OF SLAVERY: POTENTIALITIES AND LIMITS}

\section{Érica Drumond Fontes Silva* \\ PUCMG}

Resumo: José de Alencar foi um literato e político que, além das obras literárias e críticas, escreveu cartas abertas e expôs a posição conservadora em relação à libertação dos escravos e a aversão ao governo de Dom Pedro II. O presente trabalho privilegiará as Novas Cartas Políticas de Erasmo ao Imperador, escritas entre 1867 e 1868 e publicadas, sob o pseudônimo de Erasmo, em folhetos semanais. A carta, por ser um meio rápido, barato e eficiente de comunicação com o destinatário, garantia o interesse dos leitores. Buscar-se-á compreender as potencialidades e os limites das cartas abertas endereçadas ao Imperador Dom Pedro II e a caracterização desses escritos dentro dos estudos da Crítica epistolográfica (HAROUCHE-BOUZINAC, 2016), visto que as cartas possuem uma forma bastante diferenciada dentro dos seus próprios limites e é caracterizada pela instabilidade de sua forma e flexibilidade do seu uso. As cartas abertas abrem um campo de reflexão amplo em relação à expressão de um romancista sobre a sua visão do tempo e, por essa razão, elas serão estudadas no intuito de compreender algumas características do funcionamento desse tipo de mensagem.

Palavras-chave: José de Alencar. Cartas abertas. Literatura. Escravidão.

Abstract: José de Alencar was a literary and politician who, in addition to literary and critical works, wrote open letters and exposed the conservative position regarding the liberation of the slaves and the aversion to the government of Dom Pedro II. The present work will privilege the "New Political Letters of Erasmo to the Emperor", written between 1867 and 1868 and published, under the pseudonym Erasmo, in weekly leaflets. The letter, being a fast, cheap and efficient means of communication with the recipient, guaranteed the interest of the readers. This paper seeks to understand the potentialities and limits of the open letters addressed to the Emperor Dom Pedro II and the characterization of these writings within the studies of the Epistolography Criticism (HAROUCHE-BOUZINAC, 2016), since the letters have a very differentiated form within their own limits and is characterized by instability of its form and flexibility of its use. The open letters open a broad field of reflection in relation to the novelist's expression on the view of his time, and for this reason, they will be studied in order to understand some characteristics of the functioning of this type of message.

Keywords: José de Alencar. Public letters. Literature. Slavery.

\author{
* Doutoranda em \\ Literatura Brasileira \\ pela UFMG. Mestre \\ em Literaturas de \\ Língua Portuguesa \\ pela Pontifícia \\ Universidade \\ Católica de Minas \\ Gerais PUCMG. \\ E-mail: ericadfs18@ \\ gmail.com
}




\section{Introdução}

A obra política e literária de José de Alencar é vasta e diversificada, pois o autor, além de ter sido político, exerceu a advocacia e atuou na imprensa fluminense. Escreveu artigos políticos, crônicas, romances-folhetins, peças de teatro e cartas. Muitas e variadas cartas.

As cartas abertas the serviram como aliadas em diferentes momentos da carreira literária e política. Esse conjunto epistolográfico, amplo e fundamental para o entendimento do tempo e do processo de criação autoral, no entanto, não aparece, por exemplo, nas obras completas do autor romântico, organizadas em 1959 pela editora José Aguilar (hoje, Nova Aguilar).

Entre junho e agosto de 1856, como redator-chefe do Diário do Rio de Janeiro, Alencar marcou sua entrada no círculo literário fluminense ao redigir e publicar as Cartas sobre a Confederação dos Tamoios. Em seus textos literários, sempre colocava uma carta ao seu início e término como uma espécie de explicação do romance a ser lido. Como o autor se via responsável por criar uma identidade nacional das letras do país e os romances eram publicados em folhetins, a tendência em escrever cartas explicativas das motivações desses textos era um recurso frequentemente utilizado pelo romancista. Tal característica pode ser explicada pela crítica epistolográfica:

O romancista ou o dramaturgo em geral explora os recursos de funcionamentos próprios a este meio privilegiado de transmissão de informação que é a carta, verdadeiro agente dramático.

Por essa razão, a carta é com frequência forma utilizada como elemento propulsor da ficção. (HAROUCHE-BOUZINAC, 2016, p.197)

Várias foram as publicações em jornais e periódicos que, durante a década de 1860, expunham a visão de José de Alencar sobre literatura, política, escravidão e ideais sobre o funcionamento da monarquia.

Entre os anos 1860 e 1870, a divulgação das Cartas de Erasmo também foi marcante em sua trajetória, pois os textos favoreceram a sua inserção no universo político. O autor apelava ao Imperador para intervir e "ser o defensor perpétuo do Brasil, não somente nos tempos felizes, na monção das glórias e prosperidades, mas, sobretudo nas desgraças." (ALENCAR, 2008, p. 46). Essa temática também era recorrente na imprensa perante as reformas políticas e sociais que estavam em voga nesse período. Na terceira série (1867-68), composta por sete cartas, intitulada Ao Imperador, Novas Cartas Políticas de Erasmo, a emancipação dos escravos era um tema predominante, simultaneamente aos debates políticos sobre assuntos como o modo de governar e a soberania da monarquia no Brasil.

Pouca pesquisa foi feita em relação aos escritos políticos do autor e essas cartas com as suas opiniões políticas merecem atenção maior por possibilitarem a percepção de um outro José de Alencar. Tâmis Parron 
reeditou as Novas cartas políticas de Erasmo, apenas as que foram escritas entre 1867-68 e deu-lhes novo título: Cartas a favor da escravidão (São Paulo: Hedra, 2008). Até a publicação dessa edição, essas cartas não haviam sido publicadas em livro, apenas em folhetins semanais pelo próprio autor. Em 2009, o historiador José Murilo de Carvalho, através da publicação do livro Cartas de Erasmo junto à Academia Brasileira de Letras, tornou a obra política composta pelas cartas abertas, escritas entre 1865 e 1868, dirigidas ao Imperador, ao povo e aos líderes políticos Visconde de Itaboraí e Marquês de Olinda, acessíveis ao leitor.

As cartas foram publicadas no calor do debate político que envolveu a década de 1860, sobretudo entre 1865 e 1868, ano em que José de Alencar foi nomeado Ministro da Justiça.

A década de 1860 propiciou muitas discussões, como a natureza do Poder Moderador e as relações desse poder com o Executivo, a reforma da polícia e da justiça, as finanças públicas, as eleições, o sistema partidário e representativo, a Guerra do Paraguai e a abolição da escravidão.

O presente trabalho privilegiará as Novas Cartas Políticas de Erasmo ao Imperador, escritas entre 1867 e 1868 e utilizará a edição publicada, em 2008 por Tâmis Parron sob o título: Cartas a favor da escravidão.

Nessas cartas, a visão do romancista sobre a temática política, participação do Brasil na Guerra do Paraguai e a emancipação dos escravos, além das ações do Imperador em relação a tudo isso é mais evidente. Analisar tais cartas a partir de uma perspectiva política e histórica, permite aos estudiosos do romancista perceber como os acontecimentos políticos foram registrados por José de Alencar.

Alencar enfrentou, através da pena e dos discursos, todos esses temas. Nas cartas, enfatizou a corrupção do sistema representativo como principal causa da crise partidária. Pontuou e defendeu a interferência do Poder Moderador como o principal intermediário entre o povo e a aristocracia. Discutiu, sobretudo, sobre a Guerra e a abolição. Condenou, vilmente, o método proposto para a sua extinção, pois temia a desordem econômica. Defendia que era preciso sistematizar uma maneira para decretar a liberdade aos escravos e argumentou que uma organização, por etapas, por exemplo, fosse feita a fim de minimizar o impacto na economia do país.

\section{A consciência do escritor/político e a retórica da carta}

Político controverso do Segundo Reinado, tido como um dos patriarcas da literatura brasileira, José de Alencar "ocupou o proscênio durante o espaço de uma geração e, apesar de ter morrido relativamente cedo, foi o primeiro escritor que se impôs à opinião pública como figura de eminência equivalente aos governantes, aos militares, aos poderosos” (CANDIDO, 2007, p. 57). Alencar aplicou amplamente a técnica missivista na tentativa 
de consolidar seus projetos, tanto os literários (Cartas sobre a Confederação dos Tamoios, prefácios e posfácios de seus textos literários em forma de cartas destinadas ao Doutor Jaguaribe) quanto os de homem público através das cartas abertas. Tais cartas o ajudaram a traçar as trajetórias literária e política, pois se valeu do talento ao utilizar a técnica missivista para escrever aos políticos, ao chefe do Estado e ao povo:

1. Ao Imperador, Cartas de Erasmo, de 1865; a segunda edição, de 1866, incluiu uma carta Ao Redator do Diário (do Rio de Janeiro);

2. Ao Povo, Cartas Políticas de Erasmo, de 1866, acompanhadas das cartas Ao Marquês de Olinda e Ao Visconde de Itaboraí, Carta de Erasmo sobre a Crise Financeira;

3. Ao Imperador, Novas Cartas Políticas de Erasmo, de 1867-68.

As cartas abertas ganham relevância por possuírem um estilo gracioso e comunicativo. Nesses escritos, era possível maior desenvolvimento do tema sem que o autor tivesse de assumir uma linguagem mais ensaiada e elaborada. A carta, por ser um meio rápido, barato e eficiente de comunicação com o destinatário, garantia o interesse tanto de leitores políticos quanto do povo, além do interesse do principal leitor: o chefe de Estado Imperador Dom Pedro II. Em seus vários usos, as cartas têm a capacidade de revelar projetos de criação literária, experimentações linguísticas e literárias e visões do autor sobre o contexto histórico em que viveu. Mais que isso, as cartas políticas de Alencar revelam o seu engajamento político, as suas inquietações com a realidade do seu tempo e a sua ideologia.

Tais documentos possibilitam ao leitor entender como os processos políticos e sociais se transformaram em registros e as possibilidades de reflexão sobre o funcionamento do Estado e de seus integrantes no que concerne os interesses sobre a escravidão, a abolição e a monarquia através de seus ensaios, folhetins, romances e cartas.

Nesse sentido, ao observar a constituição desses escritos e tentar caracterizá-los e descrever a natureza, as propriedades e seus atributos como documentos reveladores de um tempo, é possível reconhecê-los como arquivos reveladores de uma época.

De acordo com Brigitte Diaz (2016, p. 55), a carta pode ser percebida como o relato ou até mesmo "como um documento, como um texto, como um discurso ou ainda, como um fazer, mas, na verdade, sempre é tudo isso ao mesmo tempo", ou pode ser lida como a "testemunha de uma realidade histórica, sociológica, política ou literária” no sentido próprio do termo, se tratam de textos/documentos que servem para constatar uma abordagem significativa em cada um desses âmbitos. Várias reflexões a respeito desse gênero podem ocorrer. As cartas e a linguagem utilizada têm a capacidade de fornecer um meio confiável de captar a ideia e o sentido das coisas? Brigitte Diaz (2016, p. 13) problematiza a questão: “É a carta, então, texto ou 
documento?” Pode-se pensar nesses escritos como documentos reveladores de um tempo vivido passado? Apesar dessas dificuldades de lidar com tais textos, a orientação da ciência arquivística busca caracterizar esses arquivos e perceber como o pensamento da natureza epistolar está no meio, no centro do conhecimento e da orientação do arquivo.

De acordo com Terry Eastwood (2017, p. 20), “os arquivos são criações sociais no sentido de serem um produto da sociedade humana”. São inevitavelmente criados a partir de acontecimentos, circunstâncias e evocações de seu tempo e espaço, por conseguinte, as ideias a respeito de sua natureza evocam circunstâncias variadas.

A discussão a respeito da natureza dos arquivos parte do princípio de que estamos falando de um conjunto de materiais agrupados porque falam sobre um determinado assunto na voz de uma pessoa. Quando os arquivistas falam sobre a natureza dos arquivos, eles usam o termo para fazer referência à totalidade dos documentos de uma organização ou órgão público. Várias são as discussões sobre a natureza dos arquivos e, de acordo com Terry Eastwood, tanto os conjuntos individuais de arquivos quanto os acervos coletivos sob a guarda de instituições arquivísticas serão chamados de arquivos históricos.

O conjunto de escritos de José de Alencar pode ser considerado o arquivo histórico do escritor e encontra-se digitalizado na Casa José de Alencar (CJA), espaço cultural, mantido desde 2013, pela Universidade Federal do Ceará, em Messejana, onde nasceu José de Alencar. O acervo do escritor contém artigos, crítica, romances, teatro, política e as correspondências mantidas pelo autor. Tais escritos foram produzidos entre 1845 e 1877 e revelam, além da vida, os projetos literários, as obras do autor e os acontecimentos históricos daqueles que conviveram com ele.

\section{Contexto histórico das cartas: um gênero marcando a história}

Nas cartas direcionadas ao Imperador Dom Pedro II, Alencar evidenciou o sentimento de responsabilidade que tinha em relação ao governo e às questões polêmicas no denso fim do Segundo Reinado. Assinava-as como “Erasmo”, em referência a Erasmo de Roterdã, que no século XVI iniciou a tradição da escrita de cartas que versavam sobre a educação perfeita daquele que estava destinado a ocupar o trono. Nelas estaria a relação entre um letrado conselheiro, Alencar, e um governante, Dom Pedro II. A relação entre ambos foi marcada por alguns conflitos. De acordo comCavalcanti Proença (1959, p. 31), José de Alencar herdou do pai, que era revolucionário e político influente, o gosto pela política, mas não a flexibilidade e astúcia, pois apesar de ter sido eleito deputado em 1861, reeleito várias vezes e ter sido Ministro da Justiça durante dois anos no Gabinete Conservador, José de Alencar não tinha a simpatia do imperador. É conhecido o mal-estar entre 
Alencar e Dom Pedro II, o que não é conhecido são os antecedentes que determinaram o veto à candidatura de Alencar como Ministro.

Dom Pedro II era contrário à candidatura de membros do gabinete a eleições do Senado, já os que defendiam Alencar diziam que os motivos contra o escritor eram pessoais. E há quem chegue a apontar, entre essas razões, a altivez intelectual do jovem ministro, rebelde às leis e às praxes do aulicismo que impera em todas as cortes. Visconde de Taunay, que tão longamente se ocupou do episódio, parece ter chegado à conclusão "de que tudo se resumiu numa turra, Alencar aferrando-se a um capricho, o imperador teimando, irredutível” (PROENÇA, 1959, p. 37).

José de Alencar não concordava com várias atitudes de Dom Pedro II (MAGALHÃES JÚNIOR, 1977) e usava o poder da oratória e a sua posição política para atacá-lo; várias foram as discussões: a resistência à lei do ventre livre, a denúncia do desvio de dinheiro público para jornalistas amigos do governo e a discordância da viagem do imperador com a esposa à Europa, pois o fato de deixar a princesa Isabel no poder para substituí-lo significava a possibilidade de a princesa ceder à pressão da abolição. Em 1869, candidatou-se ao senado contra a vontade do Imperador que abriu violenta campanha contra a sua candidatura, revela-se excelente orador e conquista a maioria dos votos. Após vários desentendimentos com o imperador, José de Alencar abandona o ministério da Justiça, em 1870, e volta à câmara para se opor ao Imperador. Viveu durante o período em que a nação brasileira se constituía sob vários aspectos, ou seja, três séculos após a vinda dos portugueses, quando as estruturas sociais, políticas e intelectuais do novo mundo estavam em processo de consolidação.

\section{Forma e conteúdo das cartas}

Nas cartas escritas ao Imperador, o tema central é o modo de governar seu povo, como isso refletia sobre a possibilidade da abolição da escravidão e a participação do Brasil na Guerra do Paraguai. Alencar se dizia avesso à abolição por temer os prejuízos na economia do país sem estabilidade para lidar com os libertos e o desfalque econômico dos donos de fazendas que não tinham reservas para pagar pela mão de obra. Em relação à Guerra do Paraguai, achava desnecessário o gasto retirado dos cofres públicos para a participação do Brasil.

O primeiro ponto tocado por Alencar dá o tom da epístola: o ataque à postura de Dom Pedro II, que estava motivado pela busca da fama e reconhecimento dos estrangeiros. Para agradá-los, o Imperador teria caído nas garras da vaidade e cedido a participação de seus homens à Guerra do Paraguai. Em relação à aprovação em terras estrangeiras, a nação brasileira não estaria satisfeita com os rumos adotados por Dom Pedro II, e as suas ações estariam sendo realizadas “à custa de concessões perigosas” (ALENCAR, 2008, p. 
59). O interesse de países europeus e dos Estados Unidos era problemático, e, visando à aprovação estrangeira, algumas escolhas seriam verdadeiros golpes ao país. De todos os golpes, Alencar enfatiza que existe um que seria o pior ao futuro do país: a emancipação dos escravos.

O tom de José de Alencar é, às vezes, didático e, através de uma falsa modéstia, tenta convencer o imperador sobre a importância da manutenção da escravidão no país.

Pesa-me desvanecer a grata ilusão em que se deleita vossa alma. Libertando uma centena de escravos, cujos serviços a nação vos concedera; distinguindo com um mimo especial o superior de uma ordem religiosa que emancipou o ventre: estimulando as alforrias por meio de mercês honoríficas; respondendo às aspirações beneficentes de uma sociedade abolicionista de Europa; e finalmente reclamando na fala do trono o concurso do poder legislativo para essa delicada reforma social; sem dúvida julgais ter adquirido os foros de um rei filantropo. (ALENCAR, 2008, p. 60).

Alencar problematiza as diferenciações entre a abolição na Inglaterra e suas colônias e no Brasil. Por aqui, dirá o autor, “a escravidão caduca, mas não morreu” (ALENCAR, 2008, p. 63). Afirma, ainda, que a abolição da escravidão no império inglês, em 1833, representou um problema na sociedade que via nessa instituição ainda algo muito útil, mas diferentemente do Brasil, afirma que lá "se prepararam para adaptar os escravos ao trabalho industrial” (ALENCAR, 2008, p. 79-80). O seu pano de fundo, à época, era a experiência das colônias francesas que não se prepararam para a abolição. Por isso, "a abolição da escravidão ali importara a abolição do trabalho. Ainda agora faltam às colônias francesas os braços que demanda a agricultura” (ALENCAR, 2008, p. 81). Assim, o autor tenta mostrar ao imperador a necessidade econômica ainda da atividade escrava no país. A escravidão aparecia como algo “necessário para o progresso”. Outro aspecto curioso é a questão de direitos que os escravos já possuíam, notadamente o direito à propriedade e à família. Com isso, e invocando sua religiosidade cristã, tentava amenizar sua visão em relação aos danos dessa servidão. $\mathrm{O}$ primeiro direito da pessoa, a propriedade, “o escravo brasileiro não só o tem, como o exerce, pois o senhor lhe permite a aquisição do pecúlio, a exploração das pequenas indústrias ao nível de sua capacidade” (ALENCAR, 2008, p. 90). O mais sagrado dos contratos civis, o matrimônio, também está ao alcance do escravo em nosso país. Além desses direitos, o escravo "forma sua família; o senhor a respeita e a garante” (ALENCAR, 2008, p. 91). José de Alencar reforça ainda a questão da intervenção externa, notadamente inglesa, na forma como o Brasil ia conduzindo o debate sobre a questão da escravidão. E aponta para uma contradição no discurso característico europeu que condena o trabalho escravo, mas, ainda assim, consome os produtos vindos dos países que usam dessa mão de obra. Aborda por último, a extinção natural da escravidão através da "revolução das ideias”, o que 
parece uma tentativa de isentar-se da consciência da “culpa” pela defesa da escravidão, apontando que essa prática em terras americanas foi iniciada pelos próprios europeus. Em suas palavras, "não fomos nós, povos americanos, que importamos o negro da África para derrubar as matas e laborar a terra; mas aqueles que hoje nos lançam o apodo e o estigma por causa do trabalho escravo” (ALENCAR, 2008, p. 89).

Alencar tenta determinar os reais efeitos da abolição que sucederam em todos os países que se propuseram a libertar os escravos e defende que o estudo é importante para a difícil solução do problema. Como nos romances, ele tenta projetar através dos estudos e suposições possíveis caminhos para o objeto pretendido, ou no caso, de emancipação.

Adverte que os primeiros estados a darem o exemplo da medida foram Pensilvânia e Massachusetts, em 1870. Outros estados acompanharam e tomaram a mesma conduta. O movimento abolicionista estendeu-se pelas repúblicas da América Central e do Sul. Tantos movimentos em prol da emancipação deveriam reduzi-la intensamente, porém o que aconteceu foi o contrário.

Nesse período de cinquenta anos a soma dos cativos foi constantemente crescendo. No princípio deste século pouco mais havia de dois milhões de escravos em toda a superfície da América; em 1850 orçava o número por sete milhões e meio, dos quais o maior quinhão pertencia ao Brasil e aos Estados Unidos. (ALENCAR, 2008, p.87)

Mesmo com tantos esforços para banir a escravidão, a “aparente anomalia acabrunhava a sociedade abolicionista.” (ALENCAR, 2008, p.87). A América se mostrava impotente em relação ao trabalho escravo e conseguiram apenas deslocar o trabalho servil para as cidades próximas onde era mantida.

Talvez Alencar tenha percebido que o discurso a favor da continuidade desse tipo de servidão encontrava razão de ser em uma variedade de fatores que precisassem ser compreendidos em sua complexidade e, sobretudo, no contexto problemático do Segundo Reinado com o fim da escravidão sem o devido planejamento social e econômico. Para além disso, o autor acreditava que, se não houvesse uma mudança consciente e crítica sobre o problema, quaisquer formas de bani-la seriam inválidas e frágeis.

Como todas as instituições sociais que têm radicação profunda na história do mundo e se pretendem à natureza humana, a escravidão não se extingue por ato de poder, e sim pela caducidade moral, pela revolução lenta e soturna das ideias. É preciso que seque a raiz, para faltar às ideias a seiva nutritiva. (ALENCAR, 2008, p. 89). 


\section{A reflexão moral}

As cartas a favor da escravidão escritas por Alencar suscitam nos seus leitores o pensamento conservador do autor em relação não somente a esse tema, mas a assuntos relacionados à política e ao governo da época. Qual é a possível eficácia da carta? A eficácia da carta [depende de] sua capacidade de produzir argumentações bem sustentadas, o poder que ela pode representar, afinal, fazem do domínio da escrita epistolar uma qualidade no primeiro plano na vida intelectual, social e política”. (HAROUCHE-BOUZINAC, 2016, p. 93)As cartas de Alencar somam mais efeitos em relação à leitura de suas obras e estudos em relação à visão social do tempo - visto o grande número de estudos de tais cartas nas áreas de Ciências Sociais - do que efeitos favoráveis à vontade do autor no tempo em que foram elaboradas e publicadas. Em relação à escrita de seus romances, Alencar escreveu quatro obras ficcionais em que tratava da questão escravista: dois dramas e dois romances. Os dramas estão localizados temporalmente entre suas primeiras obras, nos anos 1850, enquanto os romances foram publicados nos anos 1870.

O drama Mãe foi a única tentativa de Alencar abordar, de forma sensível, a questão da escravidão e as questões sociais e raciais que envolvem o tema. Anteriormente, o autor abordou o mesmo tema em outra obra teatral: $O$ demônio familiar, encenada em 1857, obra considerada por muitos antiescravista. Trata-se de uma comédia em que a personagem principal, Pedro, é um rapaz escravizado e ambicioso em se tornar cocheiro. Ele serve a uma família de posses módicas e imagina casar seus amos com pessoas ricas, com o intuito de que seu sonho seja realizado.

Em O tronco do ipê, romance escrito em 1871, a trama acontece em uma fazenda no interior do estado do Rio de Janeiro e tem início em 1850. As principais personagens são Mário, que vive numa fazenda como agregado, Alice, filha do dono da fazenda, e Pai Benedito. Mário é filho do antigo proprietário, morto em circunstâncias não esclarecidas. $\mathrm{O}$ atual proprietário, Barão da Espera, foi amigo do anterior, pai de Mário e, seguindo o entendimento do menino, responsável pela morte de seu pai. Pai Benedito é o protagonista negro: uma espécie de pai-de-santo, praticante de alguma religião africana e conhecedor das ervas e raízes curativas. É o representante da cultura negra, um “preto velho”, respeitado pelos moradores. Há também a presença de inúmeras personagens negras, todas escravizadas.

A naturalização da escravidão atravessa todo o romance e em especial no capítulo intitulado "O passeio", que mostra as relações entre mucamas, pajens, sinhazinhas e senhores. As relações de convivência entre senhores e escravizados, relações de subordinação e humilhação ensinadas desde a infância são expostas pelo narrador de forma natural.

No romance $O$ tronco do ipê, Alencar repete ficcionalmente argumentos utilizados em Cartas de Erasmo. No capítulo intitulado "Natal", 
Mário, ao retornar da Europa, expõe seu assombramento com a realidade do proletariado inglês. Na cena, após a festa de Natal, da qual participaram senhores e escravizados, o conselheiro, que não perdia a oportunidade de ganhar a simpatia dos fazendeiros de quem dependia sua reeleição, fez um discurso a respeito do tráfico:

- Eu queria, disse ele concluindo, que os filantropos ingleses assistissem a este espetáculo, para terem o desmentido formal de suas declamações, e verem que o proletário de Londres não tem os cômodos e gozos do nosso escravo.

- É exato, disse Mário. A miséria das classes pobres na Europa é tal que em comparação com elas o escravo do Brasil deve considerar-se abastado. Mas isso não justifica o tráfico, repulsivo mercado da carne humana. (ALENCAR, 1977, p. 287).

A cena prossegue com Mário justificando o tráfico em tempos pretéritos, por necessidade da mão de obra.

Til é o último romance de Alencar a tratar sobre a escravidão. O romance foi publicado primeiramente em 1871, em folhetins, no jornal republicano A República e, posteriormente, em livro, em 1872. Não há nenhum protagonista negro em Til, embora seja possível ouvir a voz de vários escravizados. Os principais personagens são brancos e livres.

Ao escrever as cartas e relacioná-las a esses textos sob a temática da escravidão, o autor não se intimidou em mostrar seu pensamento e deixou explícita a sua posição conservadora política e social, bem como, a sua falta de crédito em relação ao Chefe do Estado. Seus argumentos não foram capazes de produzir os efeitos desejados sobre a manutenção do poder do Império e da escravidão duas décadas antes do fim.

Alencar não viveu para ver a assinatura da lei abolindo a escravidão dos negros e nem o fim da monarquia no Brasil, mas através de seus textos é possível perceber um perfil do homem que reflete não só a sua consciência, mas uma consciência coletiva da necessidade de servidão e submissão de um povo a outro (Iracema e seu caráter servil ao português Martim Soares Moreno), um projeto de emancipação consistente que não causasse prejuízos à economia nacional e uma soberania por parte dos governantes.

\section{Considerações finais}

Compreender esses escritos dentro de sua realidade, do seu tempo, é um recurso que pode ajudar na investigação de um período histórico tão diverso do atual, e, ao mesmo tempo, compreender as querelas e lacunas mantidas ao longo dos séculos, sobretudo quando o assunto é servidão e economia. "A inscrição da carta no campo factual faz com que muitas vezes a carta seja usada para finalidades históricas ou biográficas. Assim, ela integra uma 
massa documental mais ampla, que engloba os diários íntimos, cadernetas, peças de arquivo pessoal.” (HAROUCHE-BOUZINAC, 2016, p. 24).

As cartas de Alencar podem ser lidas no tocante à percepção dos acontecimentos e podem ser fixadas ao seu projeto e criação literária, favorecendo, assim, um melhor entendimento da obra.

O contexto das cartas alencarianas é marcado por um processo de cisão política relacionada a uma tentativa de modernizar a sociedade. $\mathrm{O}$ tempo era de transição, mas José de Alencar mantinha-se firme aos ideais que correspondiam a esse tempo que estava sendo corroído.

A criação de José de Alencar é vasta e a face epistolar do escritor faz refletir a respeito das funções das missivas dentro e fora do contexto histórico. O legado epistolar alencariano pode ser estudado no sentido de compreender as trajetórias política e literária do autor e podem, sim, ser um material auxiliar no desvelamento da vida e dos ideais do autor ajudando, assim, a compreender melhor a sua obra literária.

José de Alencar foi um escritor, romancista e político que se empenhou em construir um projeto para a literatura e para o Brasil através das cartas. Ao tentar criar um projeto de Brasil compondo um quadro normativo de conduta moral que deveria ser a do imperador, a publicação das cartas indicou, sobretudo, a sua visão sobre a escravidão, além da sua defesa política dentro do paradigma do liberalismo político do século XIX.

Todos os temas trabalhados, seja o índio, o sertanejo, o regional, o local ou o urbano, são refletidos de tal forma e enovelados em seu texto às questões políticas que não se pode isolá-los ou dissociá-los sob pena de se comprometer o efeito grandioso propiciado pelo seu concerto, pelo todo. Tudo concorre para compor um imenso mosaico, civilizado, cortês, opulento no intuito de registrar, em vários níveis ou em vários gêneros, o seu retrato do presente.

Ao contar a história do seu tempo, seja através dos romances, peças de teatro ou através das cartas, quem escreve escolhe o papel social e como cada coisa será mostrada, tudo isso em consonância com o modo como experimenta as sensações do momento em que viveu.

\section{Referências}

ALENCAR, José de. Obra completa. Rio de Janeiro: José Aguilar, 1960. $4 \mathrm{v}$.

Cartas a favor da escravidão. Organização de Tâmis Parron. São Paulo: Hedra, 2008. (Série Escola da Cidade)

- Cartas de Erasmo. Organização de José Murilo de Carvalho. Coleção Afrânio Peixoto. Rio de Janeiro: Academia Brasileira de Letras, 2009. 
CANDIDO, Antonio. Iniciação à literatura brasileira. 5. ed. Rio de Janeiro: Ouro sobre Azul, 2007.

HAROUCHE-BOUZINAC, Geneviève. Escritas epistolares. Trad. Ligia Fonseca Ferreira. São Paulo: Edusp, 2016.

DIAZ, Brigitte. $\mathbf{O}$ gênero epistolar ou o pensamento nômade: formas e funções da correspondência em alguns percursos de escritores no século XIX. Tradução de Brigitte Hervot e Sandra Ferreira. São Paulo: Edusp, 2016.

DIAZ, José-Luis. Qual genética para as correspondências? Manuscrítica: revista de Crítica Genética, São Paulo, n.15, p. 119-162, 2007.

EASTWOOD, Terry. Um domínio contestado: A natureza dos arquivos e a orientação da ciência arquivística. In: EASTWOOD, Terry; MACNEIL, Heather (Org.). Correntes atuais do pensamento arquivístico. Tradução de Anderson Bastos Martins. Belo Horizonte: Editora UFMG, 2017. cap. 1. p. $19-45$

MAGALHÃES JÚNIOR. Raimundo. José de Alencar e sua época. 2. ed. Rio de Janeiro: Civilização Brasileira, 1977.

PROENÇA, M. Cavalcanti. José de Alencar na Literatura Brasileira. In: ALENCAR, José de. Obra Completa. Rio de Janeiro: José Aguilar, 1959. v. 1. p. 13-115.

Enviado em agosto/2018.

Aceito dezembro/2018. 